\title{
Pengaruh Kualitas Produk, Iklan, Elektronic Word Of Mouth Dan Citra Merek Terhadap Minat Beli Smartphone Oppo (Studi Kasus Mahasiswa Fakultas Ekonomi dan Bisnis Universitas Papua)
}

\author{
Karina Monica Ersada Siagian ${ }^{1}$, Louis S Bopeng ${ }^{2}$, Makarius Bajari ${ }^{3}$ \\ ${ }^{1}$ Alumni Jurusan Manajemen, Universitas Papua \\ ${ }^{2,3}$ Dosen Jurusan Manajemen, Universitas Papua
}

Received: Januari 2021; Accepted: Februari 2021; Published: Maret 2021

\begin{abstract}
Abstrak
Penelitian ini bertujuan untuk mengetahui pengaruh kualitas produk, iklan, elektrnic word of mouth dan citra merek terhadap minat beli smartphone Oppo. Penelitian ini merupakan penelitian kuantitatif dengan metode survei. Populasi pada penelitian ini adalah mahasiswa Fakultas Ekonomi dan Bisnis Universitas Papua, sampel sebanyak 105 responden yang ditentukan dengan teknik nonprobability sampling. Metode analisis yang digunakan adalah uji validitas dan uji realibilitas yang menggunakan AlphaCronbach. Teknik analisis yang digunakan adalah hipotesis dan regresi linear berganda. Hasil penelitian ini menunjukkan secara parsial bahwa (1) kualitas produk tidak berpengaruh terhadap minat beli smartphone Oppo, dibuktikan dari nilai t hitung sebesar -0,621 dan nilai signifikan $0,536>0,05$, (2) iklan tidak berpengaruh terhadap minat beli smartphone Oppo, dibuktikan dari nilai t hitung sebesar -1,067 dan nilai signifikan 0,289 > 0,05, (3) elektronik word of mouth berpengaruh positif terhadap minat beli smartphone Oppo, dibuktikan dari nilai t hitung sebesar 4,999 dan nilai signifikan $0,000<0,05$, (4) dan citra merek berpengaruh positif terhadap minat smartphone Oppo, dibuktikan dari nilai t hitung 4,934 dan nilai signifikan $0,000<0,05$. Dan hasil penelitian ini menunjukkan secara simultan bahwa kualitas produk, elektronic word of mouth dan citra merek berpengaruh positif terhadap minat beli smartphone Oppo dengan nilai signifikannya sebesar $0,000<0,005$.
\end{abstract}

Kata kunci: Kualitas Produk, Iklan, Elektronic Word of Mouth dan Citra Merek

\begin{abstract}
This study aims to determine the influence of product quality, advertisements, electronic words of mouth, and brand image on Oppo smartphone buying interests. This is a quantitative research with survey method. The population in this study are students of the Faculty of Economics and Business, Universitas Papua, with sample of 105 respondents, determined by the non-probability sampling technique. The analytical method used is the validity test and the reliability test using Cronbach's Alpha. The analysis technique used is the hypothesis and the multiple linear regression. The results of this study partially indicate that (1) a product quality has no effect on Oppo smartphone buying interest, as evidenced by the $t$-value of -0.662 and the significant value of $0.536>$ 0.05 , (2) advertisements have no effect on Oppo smartphone buying interest, as evidenced by the $t$-value of 1.067 and the significant value of $0.289>0.05$, (3) electronic word of mouth has a positive effect on Oppo smartphone buying interest, as evidenced by the t-value of 4.999 and the significant value of $0.000<0.05$, (4) and brand image has a positive effect on the Oppo smartphone buying interest, as evidenced by the t-value of 4.934 and the significant value of $0.000<0.05$. The results of this study simultaneously indicate that product quality, electronic word of mouth and brand image have a positive effect on the buying interest of Oppo smartphone with a significant value of $0,000<0.005$.
\end{abstract}

Keywords: Product Quality, Advertisements, Electronic Word of Mouth and Brand Image 
How to Cite: Siagian, E., M., K., Bopeng, S., L., Bajari M., (2021). Pengaruh Kualitas Produk, Iklan, Elektronic Word Of Mouth, Dan Citra Merek Terhadap Minat Beli Smartphone Oppo. JFRES: Journal of Fiscal and Regional Economy Studies, 4 (1), 32 - 36.

Corresponding author

E-mail: louis.bopeng@gmail.com

\section{PENDAHULUAN}

Di era globalisasi saat ini, perkembangan teknologi komunikasi sudah semakin berkembang dengan sangat pesat. Hal ini tidak hanya terjadi di negara-negara maju saja tapi juga di negara-negara berkembang pun juga terjadi perkembangan teknologi yang sangat pesat. Contohnya seperti di Indonesia, dimana teknologi sudah berkembang sangat pesat saat ini. Peranan teknologi komunikasi saat ini sangat berpengaruh terhadap aktivitas seseorang sehari-hari karena sangat membantu dalam memperoleh dan mencari informasi maupun bertukar informasi dengan yang lainnya. Salah satu teknologi komunikasi yang sudah berkembang saat ini dengan sangat pesat adalah munculnya telepon pintar atau yang biasa disebut smartphone.

Backer (2010) menyatakan bahwa smartphone adalah telepon pintar yang menyatukan kemampuan-kemampuan terdepan, ini merupakan bentuk kemampuan dari smartphone yang digunakan dan yang akan dapat berfungsi seperti sebuah computer dengan menawarkan berbagai fitur-fitur yang menarik seperti Personal Digital Assistant (PDA), akses internet, email, Global Positioning System (GPS). Smartphone juga memiliki berbagai fungsi lainnya yang dapat digunakan seperti kamera, video, Game, MP3 players, dan masih banyak lagi. Karena itu smartphone juga bisa dikatakan seperti computer mini (kecil) yang mempunyai berbagai manfaat serta penggunannya yang bisa digunakan dimana pun dan kapan pun. Menurut Ina Hutasoit, ketua Asosiasi Ponsel Seluruh Indonesia (APSI) menyatakan bahwa smartphone saat ini sudah sebagai keperluan pokok di samping pangan, sandang dan papan. Pesatnya pekembangan smartphone saat ini sebagai fenomena yang tidak dapat dihindari lagi, sebab saat ini rakyat sangat memerlukan informasi yang dapat digunakan untuk mengakses berbagai informasi dari internet maupun media sosial lainya. (http://techno.okezone.com).
Hingga tahun 2016 industri smartphone terus berkembang dengan sangat pesat, hal tersebut ditunjukkan dengan meningkatnya pengguna smatphone di Indonesia setiap tahun. Jumlah penduduk saat ini di Indonesia yang mencapai 250 juta jiwa merupakan pangsa pasar yang sangat besar. Lembaga riset digital marketing Emarketer memperkirakan pada 2018 jumlah pengguna smartphone yang aktif di Indonesia lebih dari 100 juta orang, (https://kominfo.go.id) yang ditampilkan dalam Gambar 1.

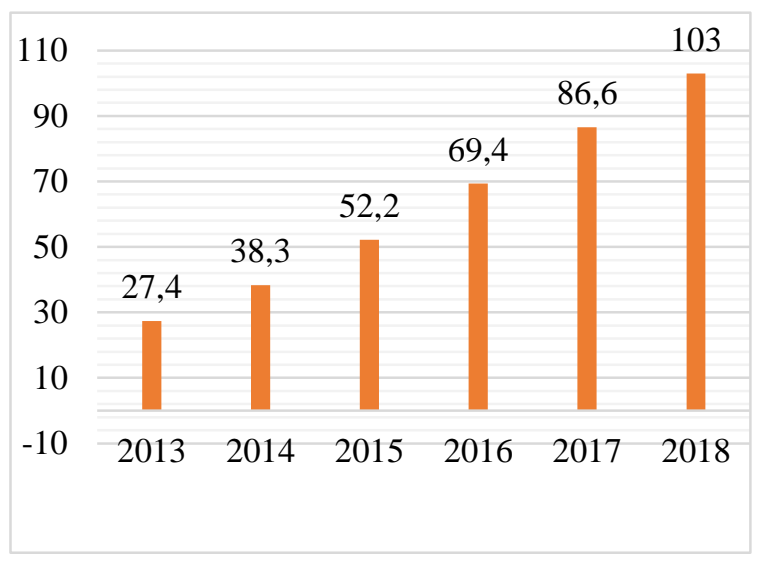

Sumber :id.techinasia.com

Gambar 1. Jumlah Pengguna Handphone di Indonesia

Gambar 1 menjelaskan bahwa yang menggunakan smartphone di Indonesia mengalami pertumbuhan yang sangat signifikan dari tahun ke tahun. pengguna smartphone di Indonesia pada tahun 2013 mencapai 27,4 juta orang, pada tahun 2014 38,3 juta orang, pada tahun 2015 yang menggunakan smartphone semakin meningkat dan mencapai 52,2 juta orang. Pada tahun tahun 2017, yang menggunakan smartphone di Indonesia semakin meningkat mencapai 86,6 juta dan pada tahun 2018 indonesia mengalami peningkatan yang sangat signifikan mencapai 103 juta orang.

Semakin meningkatnya pengguna smartphone di Indonesia, produsen Oppo harus mampu dalam membangun citra merek mereka yang kuat agar konsumen dapat mengenal 
produknya dengan baik. Penempatan merek Oppo pada benak konsumen harus dilakukan dengan startegi pemasaran yang tepat agar citra merek yang tercipta menjadi positif, dengan begitu citra positif yang dimiliki Oppo akan membuat konsumen menjadi sangat tertarik untuk dapat membeli. Pelanggan menganggap bahwa suatu produk dengan nama merek yang telah terpercaya akan lebih memberikan rasa aman dan rasa percaya diri ketika para konsumen menggunakannya.

Mahasiswa Fakultas Ekonomi dan Bisnis Universitas Papua adalah pangsa pasar yang sangat besar dalam penggunaan smartphone Oppo. Tingginya keperluan pendukung oleh para mahasiswa akan smartphone untuk menunjang proses belajar adalah hal yang sangat harus dicermati oleh para mahasiswa dalam memilih mobile phone. Banyak tipe-tipe smartphone Oppo yang dapat digunakan oleh para Mahasiswa Fakultas Ekonomi dan Bisnis Universitas Papua, dikarenakan mahasiswa/i paling banyak dalam menggunakan smartphone Oppo dalam kesehariannya.

\section{METODE PENELITIAN}

Penelitian ini merupakan penelitian dengan pendekatan kuantitatif. Penelitian ini mengambil tempat di Universitas Papua Manokwari, pemilihan lokasi di Universitas Papua dikarenakan banyaknya jumlah Mahasiswa yang menggunakan smartphone sehingga memudahkan pengambilan sampel dan kedekatan lokasi yang memudahkan penelitian ini dilakukan. Sampel yang diambil sebanyak 105 responden dan analisis yang digunakan adalah analisis regresi berganda.

\section{HASIL PENELITIAN}

\section{Hasil Uji Validitas \& Realibilitas}

Berdasarkan tabel 1 diperoleh nilai $\mathrm{r}$ hitung 0.1918. sehingga dapat disimpulkan bahwa pernyataan yang terdapat dalam kuesioner dikatakan valid. Sedangkan, berdasarkan hasil uji realibilitas pada tabel 2 di atas dilihat bahwa nilai Cronbach Alpha dari masingmasing variabel menunjukkan angka $>0.60$. maka dapat disimpulkan bahwa semua variabel dalam penelitian ini dinyatakan realibel.
Tabel 1. Hasil Uji Validitas

\begin{tabular}{|c|c|c|c|}
\hline Variabel & R hitung & R table & Ket. \\
\hline \multirow{8}{*}{$\begin{array}{l}\text { Kualitas } \\
\text { produk } \\
\text { (X1) }\end{array}$} & 0,566 & 0,1918 & Valid \\
\hline & 0,514 & 0,1918 & Valid \\
\hline & 0,546 & 0,1918 & Valid \\
\hline & 0,563 & 0,1918 & Valid \\
\hline & 0,569 & 0,1918 & Valid \\
\hline & 0,456 & 0,1918 & Valid \\
\hline & 0,430 & 0,1918 & Valid \\
\hline & 0,430 & 0,1918 & Valid \\
\hline \multirow{3}{*}{$\begin{array}{l}\text { Iklan } \\
\text { (X2) }\end{array}$} & 0,856 & 0,1918 & Valid \\
\hline & 0,891 & 0,1918 & Valid \\
\hline & 0,907 & 0,1918 & Valid \\
\hline \multirow{3}{*}{$\begin{array}{l}\text { Citra Merek } \\
\text { (X3) }\end{array}$} & 0,934 & 0,1918 & Valid \\
\hline & 0,894 & 0,1918 & Valid \\
\hline & 0,849 & 0,1918 & Valid \\
\hline \multirow{4}{*}{$\begin{array}{l}\text { Elektronik } \\
\text { word of mouth } \\
(X 4)\end{array}$} & 0,915 & 0,1918 & Valid \\
\hline & 0,934 & 0,1918 & Valid \\
\hline & 0,885 & 0,1918 & Valid \\
\hline & 0,879 & 0,1918 & Valid \\
\hline \multirow{3}{*}{$\begin{array}{l}\text { Minat Beli } \\
(\mathrm{Y})\end{array}$} & 0,881 & 0,1918 & Valid \\
\hline & 0,883 & 0,1918 & Valid \\
\hline & 0,913 & 0,1918 & valid \\
\hline
\end{tabular}

Sumber: Data primer diolah, 2019

Tabel 2. Hasil Uji Realibilitas

\begin{tabular}{lcc}
\hline \multicolumn{1}{c}{ Variabel } & $\begin{array}{c}\text { Cronbach's } \\
\text { Alpah }\end{array}$ & Ket. \\
\hline Kualitas Produk & 0.601 & Realibel \\
\hline Iklan & 0.862 & Realibel \\
\hline Citra Merek & 0.873 & Realibel \\
\hline Elektronik word of mouth & 0.922 & Realibel \\
\hline Minat Beli & 0.875 & Realibel \\
\hline
\end{tabular}

Sumber: Data primer diolah, 2019

Tabel 3. Hasil Uji Secara Simultan (F)/ ANOVA $^{\mathrm{a}}$

\begin{tabular}{lrrrcc}
\hline Model & $\begin{array}{c}\text { Sum of } \\
\text { Squares }\end{array}$ & \multicolumn{1}{c}{$\begin{array}{c}\text { Mean } \\
\text { Square }\end{array}$} & F & Sig. \\
\hline Regression & 550.344 & 4 & 137.586 & 37.160 & $0.000^{\mathrm{b}}$ \\
\hline Residual & 359.147 & 97 & 3.703 & & \\
\hline Total & 909.490 & 101 & & & \\
\hline
\end{tabular}

\section{Sumber: Data Primer yang Diolah}

Tabel 3 menunjukkan bahwa variabel kualitas produk (X1), iklan (X2), elektronik word of mouth (X3), citra merek (X4) secara bersamasma (simultan) mempengaruhi variabel minat beli (Y). hal ini ditunjukkan dengan nilai signifikan sebesar $0,000<0,05$ sehingga dapat disimpulkan bahwa H5 diterima dan Ho5 ditolak yang artinya variabel-variabel kualitas produk (X1), iklan (X2), elektronik). 


\section{PEMBAHASAN}

\section{Pengaruh Kualitas Produk Terhadap Minat Beli}

Tidak terdapat pengaruh kualitas produk terhadap minat beli pada mahasiswa Fakultas Ekonomi dan Bisnis yang menggunakan smartphone Oppo. Hal ini dibuktikan dengan nilai t hitung sebesar -0.621 dan signifikansi 0,536 dimana nilai signifikansi lebih besar dari $0,05(0,536>0,05)$. Dengan demikian H1 ditolak dan H01 diterima, artinya bahwa variabel kualitas produk tidak berpengaruh signifikan terhadap minat beli.

Berdasarkan uji hipotesis dengan menggunakan uji $t$, nilai $t$ hitung untuk koefisien kualitas produk adalah -0,621 dengan nilai signifikan sebesar 0,536 . Nilai t tabel untuk pengujian signifikan diperoleh dengan nilai alpha 0.05 dan df sebesar 105 diperoleh nilai $t$ tabel sebesar 1,659.

Berdasarkan hasil penelitian diketahui bahwa kualitas produk tidak mempunyai pengaruh secara signifikan terhadap minat beli konsumen pada smartphone Oppo, sehingga diharapkan perusahaan Oppo dapat memperhatikan kualitas produknya, agar para konsumen melihat bahwa kualitas produk dari smartphone Oppo juga baik jika dibandingkan dengan smartphone lainnya. Dengan cara ini, perusahaan dapat meningkatkan minat beli konsumen pada produk smartphone Oppo.

\section{Pengaruh Iklan Terhadap Minat Beli}

Tidak terdapat pengaruh iklan terhadap minat beli pada mahasiswa Fakultas Ekonomi dan Bisnis yang menggunakan smartphone Oppo. Hal ini dibuktikan dengan nilai thitung sebesar $-1,067$ dan signifikansi 0,289 dimana nilai signifikansi lebih besar dari $0,05(0,289>$ $0,05)$. Dengan demikian $\mathrm{H}_{2}$ ditolak dan $\mathrm{H}_{\mathrm{o} 2}$ diterima, artinya bahwa variabel iklan tidak berpengaruh signifikan terhadap minat beli.

Berdasarkan uji hipotesis dengan menggunakan uji $\mathrm{t}$ nilai $\mathrm{t}$ hitung untuk koefisien iklan adalah $-1,067$ dengan nilai signifikan sebesar 0.289 nilai t tabel untuk pengujian signifikan diperoleh dengan nilai ailpha 0.05 dan df sebesar 105 diperoleh nilai $t$ tabel sebesar 1,659.

Berdasarkan hasil penelitian dapat diketahui bahwa iklan tidak mempunyai pengaruh secara signifikan terhadap minat beli konsumen pada smartphone Oppo. Oleh karena itu, diharapkan perusahaan Oppo dapat meningkatkan promosi dengan cara membuat iklan yang menarik dan membuat isi pesan iklan yang dapat dipahami oleh konsumen sehingga dapat meningkatkam minat beli konsumen pada produk smartphone Oppo.

\section{Pengaruh Elektronik Word of Mouth Terhadap Minat Beli}

Terdapat pengaruh elektronik word of mouth terhadap minat beli pada mahasiswa Fakultas Ekonomi dan Bisnis yang menggunakan smartphone Oppo. Hal ini dibuktikan dengan nilai t hitung sebesar 4,999 dan signifikansi 0,000 dimana nilai signifikansi lebih kecil dari $0,05(0,00<0,05)$. Degan demikian H3 diterima dan H03 ditolak, artinya bahwa variabel elektronik word of mouth berpengaruh signifikan terhadap minat beli.

Berdasarkan uji hipotesis dengan menggunakan uji $\mathrm{t}$ nilai $\mathrm{t}$ hitung untuk koefisien elektornik word of mouth adalah 4,999 dengan nilai signifikan sebesar 0.000 nilai $\mathrm{t}$ tabel untuk pengujian signifikan diperoleh dengan nilai alpha sebesar 0.05 dan df sebesar 105 diperoleh nilai t tabel sebesar 1,659 .

Berdasarkan hasil penelitian dapat diketahui bahwa elektronik word of mouth mempunyai pengaruh secara signifikan terhadap minat beli konsumen pada smartphone Oppo. Namun diharapkan perusahaan Oppo harus tetap berkomitmen untuk terus dapat memberikan informasi atau pun mempromosikan produk mereka di jejaring internet sehingga dapat meningkatkan minat beli konsumen pada produk Oppo.

\section{Pengaruh Citra Merek Terhadap Minat Beli}

Terdapat pengaruh citra merek terhadap minat beli pada mahasiswa Fakultas Ekonomi dan Bisnis yang menggunakan smartphone Oppo. Hal ini dibuktikan dengan nilai t hitung sebesar 4,934 dan signifikansi 0,000 dimana nilai $\mathrm{t}$ hitung lebih kecil dari $0,05(0,00<0,05)$. Dengan demikian H4 diterima dan H04 ditolak, artinya bahwa variabel citra merek berpengaruh signifikan terhadap minat beli.

Berdasarkan uji hipotesis dengan menggunakan uji thitung untuk koefisien citra 
merek adalah 4,934 dengan nilai signifikan sebesar 0.000 nilai t tabel untuk pengujian signifikan diperoleh nilai t tabel sebesar 1.659.

Berdasarkan hasil penelitian dapat diketahui citra merek mempunyai pengaruh secara signifikan terhadap minat beli konsumen pada smartphone Oppo. Namun diharapkan perusahaan Oppo harus tetap menjaga citra merek yang dimiliki produk Oppo dengan lebih baik lagi sehingga dapat meningkatkan minat beli konsumen pada smartphone Oppo.

\section{KESIMPULAN}

Terdapat pengaruh dari variabel kualitas produk, iklan, elektronik word of mouth, citra merek secara simultan terhadap minat beli smartphone Oppo pada mahasiswa Fakultas Ekonomi dan Bisnis. Dari seluruh vaiabel, hanya variabel elektronik word of mouth dan citra merek yang berpengaruh signifikan terhadap minat beli. Sedangkan dua variabel lainnya yaitu kualitas dan iklan produk justru tidak berpengaruh signifikan pada taraf kepercayaan $95 \%$.

\section{DAFTAR PUSTAKA}

Aditya, Ayu Laksmi dkk, 2017."Pengaruh Elektronik Word of Mouth (eWOM) terhadap Minat Beli Followers Instagram pada Warunk Upnormal". Jurnal Computech dan Bisnis, Vol. 11, Juni 2017, 1-12.

Amilia,Suri.2017. "Pengaruh Citra Merek,Harga,dan Kualitas Produk Terhadap Keputusan Pembelian Handphone Merek Xiaomi di Kota Langsa". Jurnal Manajemen dan Keuangan Vol.6 No.1 Mei 2017 ISSN 2252-844X

Chistina Widya Utmi. 2010. Manajemen Ritel:Startegi dan Implementasi Ritel. Moden Jakarta: Salemba Empat.

Elysia Stephanie, 2013. "Pengaruh kredibilitas Endorser terhadap minat beli melalui sikap atas iklan pada produk Shampo L'Oreal di Surabaya". Jurnal ilmiah mahasiswa Universitas Surabaya. 2(2): h: 1-21

Neuman Lawrence W. 2003. Social Research Methods Kualitative dan Kuantitative
From Management IOI al Universitas Terbuka.

Savitri, Nyoman Wisniari. 2017."Pengaruh Celeberiti Endorser dan Iklan Melalui Media Televisi Terhadap Minat pada TokoPedia di Denpasar". E-Jurnal Manajemen Unud,Vol.6 No.8,2017: 4214-42339 ISSN: 2302-8912.

Suri, Amelia. 2017. "Pengaruh Citra Merek, Harga, dan Kualitas Produk terhadap Minat Beli Smartphone Xiomi di Kota Langsa." Jurnal Manajemen dan Keuangan, Vol.6. NO,1. MEI 2017.

Wibowo,Arif. 2015."Pengaruh Electronic Word of Mouth dan Brand Image Terhadap Purchase Intention pada Konsumen Smartphone Samsung yang Berbasis Android". Jurnal Ilmu Manajemen Vol.12 No.1 Januari 2015.

https://kominfo.go.id. Jumlah Pengguna Aktif Smartphone di Indonesia.

http://id.techinasia.com. Pertumbuhan Penjualan Smartphone Global Kuartal 1 Tahun 2015-2017.

https://id.techinasia.com. Jumlah Pengguna Smartphone di Indonesia.

https://techno.okezone.com. Informasi Pertumbuhan Smartphone di Indonesi.

Backer, Elisa. 2010. "Using Smartphone and Facebook in A Major Assessment: The Student Experience"e. Dalame-Journal of Business Education \& Scholarship of Teaching. Vol.4. No.1. Hal. 19-31. Australia: University of Ballarat. 